\title{
The Acceptance of Chinese Generation $Z$ to UGG Fur Sandals Advertisements
}

\author{
Miaomiao $\mathrm{Yu}^{1, *}$ \\ ${ }^{1}$ Donald P. Bellisario College of Communications, Pennsylvania State University, State College, 16803, United States \\ of America \\ ${ }^{*}$ Corresponding author. Email: myk5160@psu.edu
}

\begin{abstract}
The American brand UGG broke the limitation of fur materials and designed novel fur sandals, which set off a fashion trend among Chinese consumers. As young people become the main power in the consumption of fashion products, this research mainly uses questionnaires to understand the advertising acceptance of UGG fur sandals, a fashion item, among Chinese in Generation Z. This study suggests that there is a relationship between the advertising acceptance of fashionable products and the final purchase behavior of generation $\mathrm{Z}$ consumers. Besides, the content of the advertisement greatly affects the purchasing tendency of consumers in this generation. At the same time, as research on the acceptance of footwear advertising, this research also suggests the influence of other factors on the final buying behavior, such as the try-on experience. Research provides a valuable reference for future marketing strategies of fashionable brands.
\end{abstract}

Keywords: $U G G$, acceptance, Generation $Z$, advertisements

\section{INTRODUCTION}

UGG brand started in 1978, an Australian surfer Brian Smith moved to and settled in Southern California. UGG designs products with sheepskin, and its most famous product is the Classic Boot. As UGG's commitment "Feels Like Nothing Else" to all consumers, all UGG products have good quality and are extremely comfortable. A high-standard selection of materials and exquisite craftsmanship make UGG highly praised by consumers. By the mid-80s, UGG has raised a new fashionable trend about fur culture in America. Today, UGG is a popular American fashion brand all over the world. The footwear, apparel, accessories, and homeware are all adopted by both fashion elites and the public [1].

For summer fashion, UGG has design various sandals and slides since 2016. To be precise, the sandals co-branded by UGG and TEVA initially were not designed to allow consumers to wear fur sandals in summer but to allow consumers to wear sandals in autumn and winter. However, with the development of the markets, UGG began to improve and redesign its fur sandals to cater to consumer's tastes. For example, the color is more vivid, and the sandals and slides no longer wrap up the whole foot for coolness. This year UGG produces two major kinds of summer shoes "OH YEAH" with 11 colors and "DISCO SLIDE" with 8 colors [1]. The fashionable and unique design quickly aroused the attention of young people in China.

To promote the fur sandals in new seasons, UGG has a series marketing strategy. When we review the promotion activities in the Chinese market, we find that UGG paid much attention to advertising. The combination of online and offline advertising placement gives UGG more chances to attract target consumers' attention. The offline advertising location is generally the commercial center of the city. Such as the outer walls of shopping malls, large LED screens in high buildings in the city center. Additionally, UGG does not abandon the role of window advertising. For online advertising, UGG cooperates with influencers to seed products on Chinese social media. The influencers include idols, celebrities, and KOLs. The content of both the online and offline advertisings is about the fur sandals fashion outfit, distinctive fashion style with fur sandals, etc. Thus, the advertising pictures are always colorful and very eye-catching.

Another important part of the advertising is the brand spokesperson. This new summer season, UGG in 
China invites Zhou Dongyu, a young Chinese movie star, as the new ambassador. Obviously, this action is related to UGG's marketing strategy in China. The selection of ambassadors indicates that UGG has positioned the main consumers of fur sandals as the young Chinese people, specifically, people who were born between 1996 and 2010. Generation Z. In Chinese markets has called those people, and there are more and more brands that target Gen $\mathrm{Z}$ as their main consumers. Gen $\mathrm{Z}$ makes up about $15 \%$ of China's population. As the first social generation to have grown up with access to the Internet and portable digital technology from a young age, they are more likely to receive information from multi-channel. They can use online shopping more proficiently than other generations. Besides, based on one of McKinsey's surveys, China's Gen Z are optimistic, impulsive, and tend to outspend their budget when they generate buying behaviors, which means Gen $\mathrm{Z}$ have a certain consumption ability and are more susceptible to being influenced by promotional information [2].

Nowadays, there are more and more people realize the importance of advertising. The commercial advertisement in China started late, especially the footwear advertising. This is because footwear brands started and developed late in the Chinese market where is highly competitive, which makes it difficult for many footwear brands to develop quickly. This also leads to the homogenization of shoe types, target consumers, and brand image. One study emphasizes that to help Chinese footwear brands develop, people must pay attention to brand maintenance, especially to establish a clear brand image through advertising, and it's effective to create an emotional connection with consumers [3].

Chauvin and Hirschey also find and prove that the expenditure of advertising is as important as that of research and development for a company [4]. Not only the scholars but also the great entrepreneurs pay attention to the strategy of advertising. According to Xu Xindi and $\mathrm{Wu}$ Jiatong's research, they find that advertising could help most companies improve their publicity and the value of brands. Additionally, as the publicity of the enterprise has been increased, the enterprise has the right to control the price of their product which ultimately increases the enterprise's revenue [5].

Although there are few studies about the advertisement of footwear, there are many studies on clothing advertising. In Huang's research, the researcher studied the influence of clothing advertising on Chinese consumer's clothing choices. The result shows that half of the participants agree that advertisements influence their choices, and $10 \%$ of participants believe advertisements about clothing influence their choice to a large extent [6]. However, the research still has several limitations, such as her study argues that there exists a positive relationship between advertising and the choice of clothing. Still, she did not analyze whether there is an emotional tendency in this choice. That is significant, because according to the theory of reasoned action

(TRA) developed by Fishbein and Ajzen in 1975, people's attitude, or emotional tendency, can be used to predict the final behavior, which means that consumers' attitudes of one advertisement may be consistent to consumers' final buying behavior [7], and that will ultimately affect the sales of the product. These aspects can help us understand the acceptance of advertising.

In addition to attitudes that affect the acceptance of advertisements, another factor related to the acceptance of advertisements is the incentive mechanism. The incentives include coupons, free using and so forth. In many related studies, advertisement acceptance will be much higher if the advertisement contains incentives [8]. In 2006, Michael Hanley, Michael Becker, and Jackie Martinsen collected data about teenagers' advertising acceptance when the respondents were asked, "Under which of the following conditions would you consider accepting ads on your cell phone?" Most people (29\%) said that if they got something free [9].

Another focus of the theme is Generation Z (Gen Z). Gen $\mathrm{Z}$ is an individual who was born in the mid-1990s to the early 2000s. Individuals of Gen $Z$ have been called "digital natives" because they are the first generation who has grown up with the Internet $[10,11]$. As the audience of advertising and as consumers, Gen $\mathrm{Z}$ could be characterized by 4 trends: 1) A focus on innovation, 2) An insistence on convenience, 3) An underlying desire for security, and 4) A tendency toward escapism [12]. Today, Gen $Z$ has become the target consumer of many trendy products. However, there is little study of generation $\mathrm{Z}$ as a consumer in the Chinese market due to various reasons.

These studies and theories above help us understand some background information in advance. However, there still exist some research gaps. We find that although there is much literature about the acceptance of advertisement, few studies have been conducted on the acceptance of Chinese footwear advertising. Besides, in the research on the acceptance of advertising, the consumer's attitude is not focused on. Moreover, there is little study about the consumer from Gen Z, who is the target consumer of many fashionable products today. They need to be given more attention.

Our purposes are we hope that after studying the Chinese Generation Z's acceptance of UGG fur sandals advertising, marketers could understand the young consumers' ideas, which could help them formulate much perfecter marketing strategies for their clients. Additionally, the research can also help Chinese and even global footwear brands understand footwear market trends, and they can upgrade and innovate more 
fashionable styles that are in line with consumer preferences.

To achieve the expected purposes of this study and let the significance of this study can be put into practice. This research will study Chinese Generation Z's acceptance of UGG fur sandals advertisements through the questionnaire.

\section{METHODOLOGY}

To clearly analyze the acceptance of Chinese Gen Z to the advertisements of UGG's Fur Sandals, the methodology of this research is a questionnaire that belongs to the quantitative method.

A questionnaire collects the information of participants by asking them to answer relevant questions about the topic and purposes of one research, which help researchers learn more about the related opinion, attitude of participants. Compared with other types of surveys, the questionnaire is the most inexpensive and effective method, and especially recently, researchers can distribute questionnaires via computers. With the help of the Internet, researchers could save a lot of time and reach more participants from the extensive range. When the number of participants increases, the number of valid questionnaires will also increase, conducive to researchers analyzing the data and drawing more objective conclusions. Based on these characteristics of the questionnaire, the questionnaire method would help draw research conclusions more effectively.

As the audience of the research topic is about Chinese Generation Z, the best way is to use Chinese social media to deliver the questionnaire. Besides, it's crucial to choose social platforms with more young users so that the questionnaire can get more valid results about Gen $\mathrm{Z}$ participants. To acquire enough data for analysis, the questionnaire open-to-participate period to 3 days. After 3 days, there were 142 questionnaires and 132 valid questionnaires. Among them, 95\% of the participants were aged between 17 and 26, which is within the age range of generation $\mathrm{Z}$.

\section{RESULTS}

Based on the 132 valid questionnaires, 108 participants expressed they have noticed the fur sandals of UGG. According to all the approaches of the awareness of fur sandals, celebrities or influencers recommendation, and official advertising in social media are the most prevailing ways. Promoting a new product by influencers or celebrities and online promotions have become an effective tactic to touch the target audience from Gen $\mathrm{Z}$.

In terms of the results about the number of people who have seen the official advertisements, it suggested that 87 people have seen that. The ratio of knowing fur sandals by official advertisements to by other ways is nearly 4 to 5 . According to the results of these 87 participants who have seen the official advertisements, 20 people strongly agree, and 42 people agree that the content of these advertisements influences their impression of fur sandals. For Gen Z, the influence of advertisements would never be neglected.

When checked the results of further questions, which suggested there were 45 participants of all the 87 participants who have seen the official advertisements expressed they are more inclined to agree with positive adjectives - fashionable, soft and cute, aesthetic -for fur sandals. On the contrary, among the 21 participants who have not seen the official advertisements ever, only 5 people agree with these 3 adjectives. Advertising can guide people's impression and evaluation of products.

Besides, among those 87 participants who have seen the official advertisements, only 9 people clearly proclaimed they would never buy the fur sandals; 45 people who agree with positive adjectives of fur sandals suggested they must buy at least one pair of fur sandals. Among the 21 participants who have never seen the advertisements, $4 / 5$ people selected the neutral choicedepending on circumstance. These results suggest the advertisement is related to the willingness to buy.

By further analysis of the relationship between advertisements and the willingness of buying, the results help us understand that if the design and content of the advertisement are more in line with the consumer's perception, then the consumer is more likely to buy the product in this advertisement. Moreover, among 32 participants who expressed they will 100 percent buy fur sandals (including all the people who know fur sandals), 25 people suggested they really agree that the design and content of advertisements influence their attitude to buy such sandals.

Including the advertisements, personal try-on experience, and price are also the most important factors that determine whether consumers will eventually buy the product. Of the 87 participants who have seen the official advertisement, 46 said that the advertisement's content is in line with their evaluated price for fur sandals.

\section{DISCUSSION}

After reviewing the results of the questionnaire, we can simply summarize there exists a relationship between the advertising of fur sandals and the buying behavior of consumers from Gen $Z$. The level of consumer acceptance of UGG fur sandals advertisements can be reflected in whether they have a positive evaluation of the fur sandals and whether they agree with the information conveyed in the advertisement. Together with the characteristics of the 
product itself, all the reflections will affect the final sales of fur sandals.

Nearly $4 / 5$ participants said they knew the fur sandals, which suggests that the exposure of fur sandals is comparatively high. If we pay attention to the advertising strategy, it is easy to find that the UGG used the multi-channel network (MCN)to advertise the new season's fur sandals. This is the best way to largely touch their target consumers, Gen Z. Especially, the online advertising by social media celebrities and influencers. Gen $\mathrm{Z}$ is a generation that has grown up with the Internet, and online advertising has a greater impact on them than on other age groups. Obviously, the high exposure of UGG's advertisements about fur sandals promotes the sales of fur sandals to a large extent. Let consumers have an awareness of one product is the first step of finally buying behavior. This analysis based on the tendency to accept advertisements of target consumers is the reason why UGG advertisements can have high exposure.

Advertisement is the first impression of a certain product in the minds of consumers. Especially when a new product appears, there has not existed any comment about a novel product. Brands need to create an image for new products through advertising. The advertising of UGG fur sandals is a great example. To show the characteristics of fur sandals- fashionable, soft, and cute, UGG chose a young brand spokesperson to appear in the official advertisement. This spokesperson is wellknown in Gen Z, and people's impressions of her are mostly about cute and smart. These impressions are what UGG wants consumers to have on fur sandals. Such a strategy will link consumers' perceptions of fur sandals with the spokesperson's image and eventually promote people to have a good unified impression of fur sandals.

According to the analysis of the adjectives of fur sandals evaluation, we can know that the advertisement's content will determine people's evaluation of the product. What's more, as a kind of visual art, advertising design has a great impact on people. Especially, choosing a suitable color tone according to the product's characteristics is an indispensable factor in a good advertising design. This is actually very easy to understand. For example, a burger restaurant has launched a new burger. If the poster mainly uses red hue and "fire" colors, even if you have not eaten this burger, you will subconsciously think this new burger is mighty spicy. I guess this is the major reason why the main colors in advertisements of UGG fur sandals are all gentle colors, such as taro purple. The gentle light colors make people feel that fur sandals are soft, and the furry features are further magnified.

At the same time, when people have established a good awareness and impression of fur sandals, they will be more likely to buy this product. Suppose consumers agree with the design concept of the product and love the appearance of the product. In that case, they will think that this product can bring them more value, such as letting consumers feel that wearing fur sandals can make them more fashionable. Therefore, the product builds a good image of the product through advertising. Consumers would be much more agree with the value of the product and ultimately lead to the purchase behavior.

As the best indicator for evaluating advertising acceptance, buying behavior will also be affected by other factors. These factors and advertising together lead to the final purchase behavior. For fur sandals, we should consider that a very important factor that leads to the sales of footwear products, comfort. Questionnaire results suggest that try-on experience is still the pivotal factor that affects whether consumers ultimately buy or not. This factor is something that all brands of footwear products should pay attention to. When your advertisement is attractive enough, you should also pay attention to improving customer satisfaction with the try-on experience during the sales process.

Additionally, for Chinese consumers, especially young generation $\mathrm{Z}$ consumers, the price of the UGG brand is not low. Therefore, the price of fur sandals is another major factor that ultimately affects buying behavior. Therefore, if UGG wants to increase the sales volume of fur sandals among consumers from Gen Z, UGG should focus more on thinking about some marketing strategies to reduce product prices. For example, consumers from Gen $\mathrm{Z}$ are very proficient in online shopping, and UGG could open many multiplatform online sales channels to reduce offline operating costs. Besides, UGG could rely on the promotion activities of China's developed online shopping platforms, such as Taobao and the 11.11 national online shopping festival every year, launching attractive discount prices to win by volume.

\section{CONCLUSION}

This research aims at understanding the advertising acceptance of UGG fur sandals, a fashion item, among Chinese in Generation Z. By studying the advertising channels of UGG fur sandals, we can understand that multi-platform advertising has helped fur sandals increase the exposure rate among young consumers, especially, online advertising effectively reaches more consumers from Generation Z. Besides, through the questionnaire, we can clearly understand that advertising has an impact on Chinese Generation Z consumers' buying behavior. Young consumers' impression of the fashionable product is largely determined by the impression of the product's advertisement. The spokesperson in the advertisement, the color of the advertisement, and so forth will affect people's impression of the product. The higher the 
degree they agree with the content of the advertisements, the more likely to buy the products. However, due to brand pricing and product functionality differences, purchasing behavior is not only determined by advertising. Just like the sandals we studied, try-on experience about footwear products is also an important factor for consumers to decide whether to buy or not. Therefore, when brands and marketers are setting up marketing strategies for young consumers and increasing the emphasis on advertising, they also need to set product prices reasonably and increase consumer satisfaction with the try-on experience. Of course, young people live in different cultural backgrounds have different attitudes towards a new trend of fashion products. To learn more about the advertising acceptance and consumption attitudes of Generation $\mathrm{Z}$ consumers in different regions, we need to do a more extensive study.

\section{REFERENCES}

[1] UGG, Our Story, retrieved 9th, August, 2021 from https://www.ugg.com/our-story.html

[2] Jia Zhou, Felix Poh, Cherie Zhang, Daniel Zipser, China's Gen $Z$ are coming of age: Here's what marketers need to know, McKinsey \& Company, retrieved 9th, August, 2021 from https://www.mckinsey.com/cn/our-insights/ourinsights/chinas-gen-z-are-coming-of-age-hereswhat-marketers-need-to-know ,(2020).

[3] Yang Tong, Research on Brand Maintenance of Footwear Enterprises, Shanxi University of Science \& Technology (2014).

[4] Chauvin, Keith W., and Mark Hirschey, Advertising, $R \& D$ Expenditures and the Market Value of the Firm, Financial Management, (2021).

[5] Xu Xindi, and Wu Jiatong, The Impact of R\&D and Advertising Investment of Chinese Footwear, Cooperative Economy and Technology, (2021).

[6] Huang Yaqing, Current Position and Development Study of Chinese Clothing Advertisement, 1, (2007).

[7] Ajzen Icek, and Martin Fishbein. Understanding attitudes and predicting social behavior, New Jersey: Prentice-Hall, (1980).

[8] Liu Hongyan, and Fu Shenglan, Research on the Factors Influencing the Acceptance of Mobile Advertising — Based on the Perspective of College Students' Mobile Advertising Experience, Soft Science, (2014).

[9] Hanley, Michael, M.Becker, and J.Martinsen, actors influencing mobile advertising acceptance: will incentives motivate college students to accept mobile advertisements? International Journal of Mobile Marketing, (2006)

[10] Turner, Anthony, Generation Z: Technology And Social Interest, Journal of Individual Psychology, (2015).

[11] Twenge, Jean Teens are sleeping less - but there's a surprisingly easy fix. The Conversation, (2017).

[12] Wood, Stacy. Generation $\mathrm{Z}$ as consumers: trends and innovation. Institute for Emerging Issues: NC State University (2013). 